Natural Hazards and Earth System Sciences, 5, 733-740, 2005

SRef-ID: 1684-9981/nhess/2005-5-733

European Geosciences Union

(C) 2005 Author(s). This work is licensed

under a Creative Commons License.

\title{
Great landslide events in Italian artificial reservoirs
}

\author{
A. Panizzo ${ }^{1}$, P. De Girolamo ${ }^{1}$, M. Di Risio ${ }^{2}$, A. Maistri ${ }^{3}$, and A. Petaccia ${ }^{4}$ \\ ${ }^{1}$ Dipartimento di Ingegneria delle Strutture delle Acque e del Terreno DISAT, L'Aquila University, 67040 Monteluco di Roio \\ (AQ), Italy \\ ${ }^{2}$ Dipartimento di Ingegneria Civile, Università degli Studi di Roma "Tor Vergata", Via del Politecnico 1, 00133 Roma, Italy \\ ${ }^{3}$ Registro Italiano Dighe, Ufficio Geologia Applicata, Via Curtatone 3, 00185 Rome, Italy \\ ${ }^{4}$ Registro Italiano Dighe, Ufficio Idraulica, Via Curtatone 3, 00185 Rome, Italy
}

Received: 1 March 2005 - Revised: 1 September 2005 - Accepted: 2 September 2005 - Published: 30 September 2005

Part of Special Issue "Tsunami hazard from slope instability"

\begin{abstract}
The empirical formulations to forecast landslide generated water waves, recently defined in the framework of a research program funded by the Italian National Dam Office RID (Registro Italiano Dighe), are here used to study three real cases of subaerial landslides which fell down italian artificial reservoirs. It is well known that impulse water waves generated by landslides constitute a very dangerous menace for human communities living in the shoreline of the artificial basin or downstream the dam. In 1963, the menace became tragedy, when a 270 millions $\mathrm{m}^{3}$ landslide fell down the Vajont reservoir (Italy), generated an impulse wave which destroyed the city of Longarone, and killed 2000 people.

The paper is aimed at presenting the very satisfactorily reproduction of the events at hand by using forecasting formulations.
\end{abstract}

\section{Introduction}

The evaluation of impulsive waves triggered by landslides in artificial reservoirs is of the utmost importance in the planning and the management of the dam and the artificial reservoir. In artificial basin where landslide risk exists, the water is kept well below the maximum level, thus avoiding the dam overtopping and the runup on the shorelines of the potential impulse wave.

These waves are a particular type of tsunamis water waves, and have been studied in the past using mathematical theories (Stoker, 1957; Prins, 1958; Kranzer and Keller, 1960; Le Méhauté and Wang, 1996), physical model experiments (Wiegel, 1955; Wiegel et al., 1970; Kamphuis and Bowering, 1972; Huber and Hager, 1997; Watts, 1997; Walder et al., 2003; Fritz et al., 2004) and numerical simulations (Heinrich,

Correspondence to: A. Panizzo

(panizzo@ing.univaq.it)
1992; Watts, 1997; Monaghan and Kos, 2000; Watts et al., 2005). Despite this body of works, the topic still requires researches, and the presence of many studies from last three years testifies that scientists' endeavors are directed toward the definition of even more accurate forecasting models.

In the above introduced context, the Italian dam register RID (Registro Italiano Dighe) funded a research program, based on experimental, numerical and mathematical studies, aimed at forecasting the principal parameters of landslide generated waves as a function of assumed parameters of the falling landslide and the water body. One of the carried out experimental studies defined empirical formulations forecasting the principal features of impulse water waves propagating in a three dimensional water body (Panizzo, 2004). At the same time, an experiment carried out in a two dimensional wave flume was used to define the impulse wave runup on plane slopes (Di Risio and De Girolamo, 2004; Di Risio, 2005). Results from these experiments have been here used to characterize the principal features of subaerial landslide generated waves observed during three very famous and tragic events occurred in 1959 at the Pontesei (Italy) artificial reservoir, and in 1960 and 1963 at the Vajont (Italy) artificial reservoir.

The paper is organized as follows: the second section introduces a decription of the carried out experimental studies and presents obtained formulations. The third section presents the landslide event occurred at the Pontesei reservoir the 22 March 1959, focusing on the characterization of both the kinematic of the landslide movement and the features of the impulse generated waves. Similar studies are presented for the landslide events occurred at the Vajont reservoir the 4 November 1960 and 9 October 1963, which are reported in the fourth section. Finally, conclusions are drawn in the fifth section. 


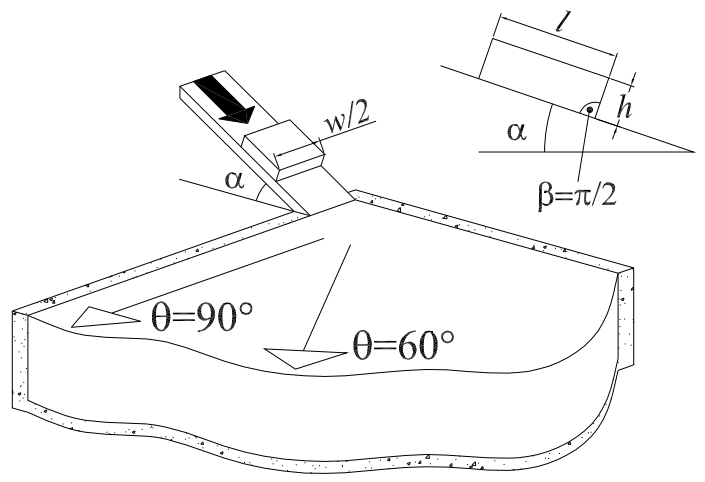

Fig. 1. Sketch of the experiment on the study of landslide generated impulse waves propagating in a three dimensional water body.

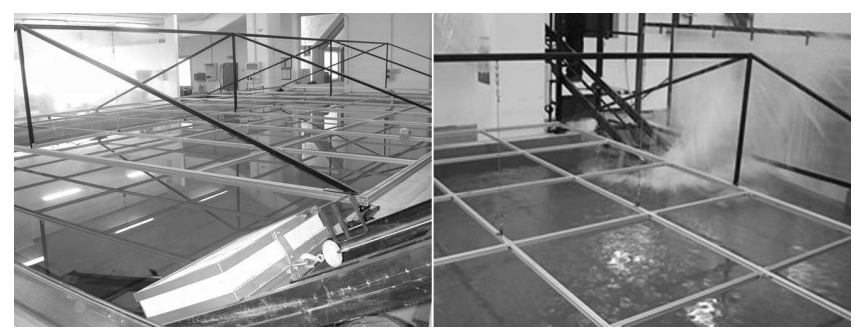

Fig. 2. Pictures from the three dimensional physical model. On the left, solid block landslide model and wave tank. On the right, impact of the landslide model with water.

\section{Experimental formulation to forecast landslide gener- ated waves}

The studies on both the three dimensional physical model and the wave runup on plane slopes were carried out in the Laboratory of Environmental and Maritime Hydraulic LIAM (Laboratorio di Idraulica Ambientale e Marittima) of L'Aquila University. The studies were targeted at defining empirical formulations able to correlate the main parameters of impulse generated water waves to those of the landslide movement and the reservoir. The landslides were modelled as solid blocks with zero porosity. Complete descriptions of the carried out experimental activities and defined formulations are reported in the works of Panizzo (2004), Panizzo et al. (2005), Di Risio and De Girolamo (2004) and Di Risio (2005). Here only a brief description on both the performed experiments and defined formulations will be provided.

As far as the three dimensional physical model is concerned, Fig. 1 reports a sketch of it, while Fig. 2 shows two pictures of the experimental wave tank and the landslide physical model (left panel) and of one of the performed experiments (right panel). With reference to Fig. 1 the landslide height $h$, width $w$, impact velocity $v$, the ramp inclination angle $\alpha$ and the local water depth $d$, and the time of underwater landslide motion were considered as variable input parameters of the study. The maximum wave height $H_{\max }$ and its wave period $T_{\max }$ have been referred to as parameters characterizing the water motion. $H_{\max }$ and $T_{\max }$ were considered
Table 1. Experimental variables to study landslide generated water waves propagating in a three dimensional water body.

\begin{tabular}{ccccccc}
\hline$h(\mathrm{~m})$ & $w(\mathrm{~m})$ & $v(\mathrm{~m} / \mathrm{s})$ & $\alpha(\mathrm{rad})$ & $d(\mathrm{~m})$ & $r(\mathrm{~m})$ & $\theta(\mathrm{rad})$ \\
\hline 0.09 & 0.30 & 2.8 & 0.279 & 0.4 & 1.05 & 0.0 \\
0.18 & 0.60 & 3.7 & 0.453 & 0.8 & 2.05 & $\pi / 6$ \\
& & 4.4 & 0.628 & & 3.05 & $\pi / 3$ \\
& & & & & 4.55 & $\pi / 2$ \\
& & & & & 6.05 & \\
\hline
\end{tabular}

Table 2. Ranges of the selected non dimensional parameters.

\begin{tabular}{cccccc}
\hline$w h / d^{2}$ & $v / \sqrt{g d}$ & $\cos (\theta)$ & $\sin (\alpha)$ & $r / d$ & $t_{s}^{*}$ \\
\hline 0.042 & 0.999 & 0.0 & 0.276 & 1.312 & 0.39 \\
0.675 & 2.221 & 1.0 & 0.588 & 15.125 & 5.112 \\
\hline
\end{tabular}

in a system of polar coordinates $r$ and $\theta$, being $r$ the distance from the landslide impact point and $\theta$ the angle from the landslide velocity vector.

On the basis of results from past studies (Kamphuis and Bowering, 1972; Huber and Hager, 1997) the physical variables were assumed in the experimental ranges defined in Table 1 , and the non dimensional groups have been defined considering the local water depth $d$ as the length scaling parameter. A particular importance has been given to the time of underwater landslide motion, as pointed out by Watts (1998) and Walder et al. (2003). Indeed, a monoaxial accelerometer was placed on the back of the landslide model, and the landslide velocity and displacement time series have been obtained by integration. As far as the non dimensional time of underwater landslide motion is concerned, defined as $t_{s}^{*}=t_{s} \sqrt{g / d}$, it can be expressed as:

$t_{s}^{*}=0.43\left(\frac{w h}{d^{2}}\right)^{-0.27}\left(\frac{v}{\sqrt{g d}}\right)^{-0.66}(\sin \alpha)^{-1.32}$

The landslide geometry has been summarized considering the non dimensional parameter $A_{w}^{*}=w h / d^{2}$. Table 2 reports the ranges of non dimensional parameters of the performed experimental study. Since each test was repeated twice in order to reduce experimental errors, 288 tests were carried out, producing a database of 2880 wave records from a system of 10 wave gauges set in the used wave tank.

The analysis of experimental data was carried out taking into account results from the works of Kamphuis and Bowering (1972) and Huber and Hager (1997) and the scaling analysis approach presented by Watts (1998) and Walder et al. (2003). All these experimental studies presented empirical formulations able to characterize the features of the generated impulse waves as a function of a certain number of involved physical parameters. Considering $A_{w}^{*}$ as the main parameter in the fitting procedure, and using the Gauss-Newton 
Table 3. Experimental program of the study of impulse generated waves runup.

\begin{tabular}{ccc}
\hline$d(\mathrm{~m})$ & $\gamma(\mathrm{rad})$ & $L_{p}(\mathrm{~m})$ \\
\hline 0.06 & 0.384 & 0.85 \\
0.10 & 0.645 & 1.30 \\
0.18 & 1.466 & 1.85 \\
\hline
\end{tabular}

optimization approach of the experimental data, a new formulation for the maximum generated wave height $H_{\max }$ has been defined in Panizzo et al. (2005), which reads:

$$
\begin{aligned}
& H_{\max } / d=0.07 \cdot\left(t_{s}^{*} / A_{w}^{*}\right)^{-0.45}(\sin \alpha)^{-0.88} . \\
& \exp (0.6 \cos \theta)(r / d)^{-0.44}
\end{aligned}
$$

and presents a mean error equal to 0.0002 from experimental data, and a correlation parameter $R^{2}=0.79$. As one would expect, $H_{\max } / d$ increases with the landslide front surface, while decreases when $r / d$ or $t_{s}^{*}$ increases. The directional distribution presents a maximum at $\theta=0.0$, as expected. The parameter $l / d$ has been neglected, as it doesn't improve the correlation with experimental data.

The formulation forecasting the wave period of the wave presenting the maximum height has been defined as:

$T_{\max } \sqrt{g / d}=2.50 \cdot t_{s}^{*-0.22}(\sin \alpha)^{-0.25}(r / d)^{0.17}$

Equation (3) presents a mean error equal to 0.22 and a correlation parameter $R^{2}=0.64$ with the experimental data.

As far as the experimental study on the runup of impulse water waves on plane slopes is concerned, Fig. 3 shows the sketch of the realized physical model and the assumed landslide mechanism, which is the well known "Scott Russell Wave Generator". The slope inclination angle $\gamma$, the distance of the slope from the impact point $L_{p}$, the local water depth $d$ were considered the experimental parameters influencing the observed runup $r_{u}$. Table 3 reports the values of $\gamma, L_{p}$ and $d$ assumed in the experimental study (27 tests repeated twice). It is to be noticed that parameter $L_{p}$ no longer appears in the forecasting formulation as its variability was used to change the incident perturbation features at the beach toe, i.e. the incident wave height $H$ and wave period $T$. The non dimensional incident wave height ranged in $(0.18 ; 0.70)$ and non dimensional incident wave period ranged in (7.48; 15.60), hence the following empirical formulation is valid for a wide range of wave type, such as solitary, cnoidal and linear waves. The analysis of the observed wave runup on the sloped plane has been carried out by digital analysis of the recorded movies of the water oscillations, as showed by Fig. 4. On the basis of the experimental results, the following formula forecasting the value of the impulse water waves runup has been defined:

$$
\frac{r_{u}}{d}=1.37\left(\frac{H_{\max }}{d}\right)^{1.51}\left(T_{\max } \sqrt{\frac{g}{d}}\right)^{0.47}(\sin \gamma)^{0.26}
$$

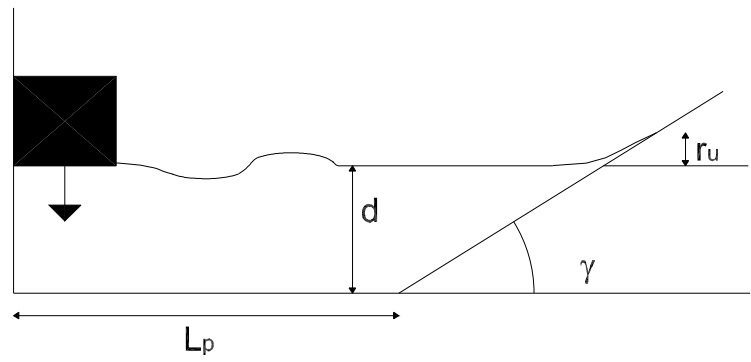

Fig. 3. Sketch of the physical model used to study the runup of landslide generated water waves on plane slopes.

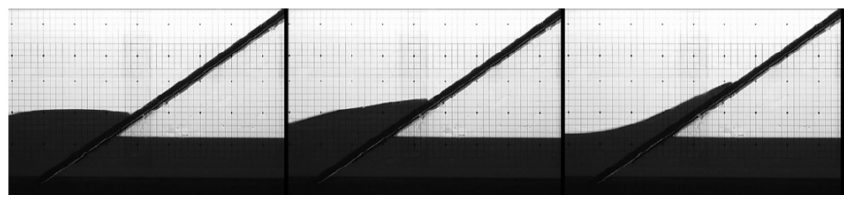

Fig. 4. Images from one of the performed experiments on the runup of landslide generated water waves.

The proposed empirical formulation presents a mean error to the observed values equal to 0.11 and a correlation parameter $R^{2}$ equal to 0.96 . Although several empirical formulas forecasting $r_{u}$ have been presented in the past (Synolakis, 1987; Tadepalli and Synolakis, 1994; Muller, 1995), for the first time the period $T$ of the incident impulse water wave has been considered as influencing factor. In the present study, the formulation forecasting the wave runup (Eq. 4) has been applied considering the height and period of the maximum generated wave.

\section{9 event at the Pontesei reservoir}

On 22 March 1959, at the Pontesei artificial basin, an impulse wave was generated by the falling of a 5 million $\mathrm{m}^{3}$ landslide into the water. A man, who was riding a bike along the street on the opposite side of the basin, was killed by the water wave runup. The event is described in the work of Semenza (2002). Figure 5 shows a picture of the dam and the artificial reservoir as it is today, where the 1959 landslide is visible on the upper part of the figure.

The 1959 event didn't cause damages to the dam, but reduced the basin capacity of about the 50\%. At that time the dam was (and still is) $93 \mathrm{~m}$ high, the basin capacity was equal to 9.09 million $\mathrm{m}^{3}$ before the 1959 landslide, while now it is equal to 5.8 million $\mathrm{m}^{3}$. On 22 March 1959 the basin contained about 6.10 million $\mathrm{m}^{3}$ of water. Considering the descriptions in the works of Semenza (2002) and Caratto et al. (2002), it is possible to make reasonable assumptions about the values of the principal landslide and basin parameters involved in the event at hand. Firstly, the slope inclination angle of the landslide rupture surface (parameter $\alpha$ ) can be assumed equal to $5^{\circ}$. Referring to the work of Semenza (2002), the landslide front width $w$ and height $h$ were 


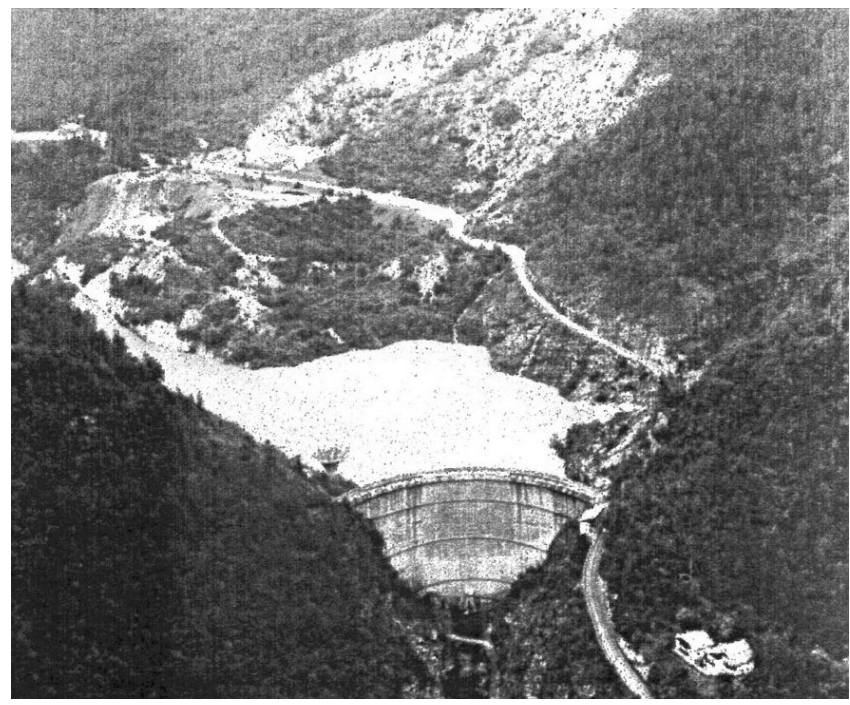

Fig. 5. Picture of the Pontesei dam and artificial reservoir as it appears today. The 1959 landslide is clearly visible in the upper part of the picture.

$400 \mathrm{~m}$ and $47 \mathrm{~m}$, respectively. About this $h$, the landslide sliding bed was defined by means of soil drillings carried out by ENEL (the national society for electricity supply in Italy) in 1969. From the manuscript of Caratto et al. (2002) it can be assumed that the entire landslide movement took about $3-5$ min to fully develop, covering a distance equal to $120 \mathrm{~m}$. Assuming a given uncertainty on the time of underwater landslide motion, we can refer to a slow landslide with $t_{s}$ of about $1 \mathrm{~min}$. The value of the local water depth $d$ can be evaluated by considering that the water surface, at the moment the landslide fell down into the water, was $787 \mathrm{~m}$ above the m.s.l., while the bottom of the reservoir was $740 \mathrm{~m}$ above the m.s.l. The application of the formulation forecasting the maximum wave height is here carried out considering $\theta=0.0^{\circ}$, as it is known for sure that the generated impulse wave reached the street which was on the opposite side of the basin, right in front of the landslide, at a distance from the impact point equal to $175.0 \mathrm{~m}$. The inclination angle of the opposite slope $\gamma$ is assumed equal to $40.0^{\circ}$.

Considering the above introduced values of the principal parameters involved in the phenomenon, Fig. 6 shows results obtained applying the forecasting formulations with a given uncertainty on the time of underwater landslide motion, which is variable in $(60.0 ; 80.0) \mathrm{s}$. The thin black line reports the values of the estimated maximum generated wave height $H_{\max }$, while the thick line reports the values of the estimated $r_{u}$. Results shows $r_{u}$ variable in the range (17.0; 20.0) $\mathrm{m}$, while the vertical distance between the street and the water surface was equal to $18.0 \mathrm{~m}$ at the moment the landslide fell down. It is to be considered that the water not only reached the street, but also killed a man who was riding a bike. We believe the occurred $r_{u}$ had a value very close to $20.0 \mathrm{~m}$.

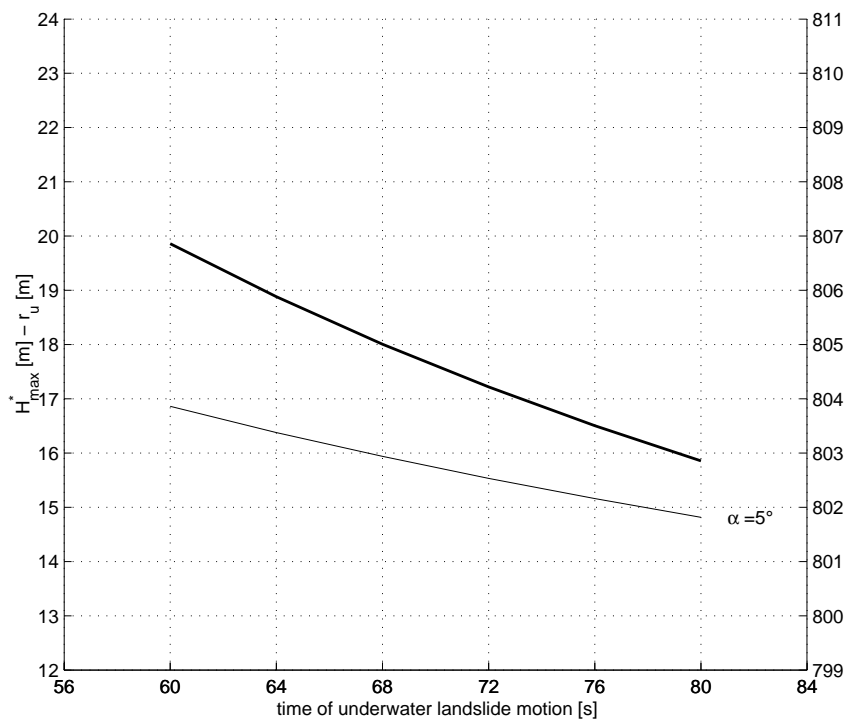

Fig. 6. Estimated maximum wave height $H_{\max }$ and runup $r_{u}$ generated by the landslide event of 22 March 1959, at the Pontesei reservoir. The secondary y-axis refers to levels above the m.s.l.

\section{0 and 1963 events at the Vajont reservoir}

The construction of the artificial reservoir in the Vajont valley triggered the instability of the slopes, and consequently two huge rock landslides which fell into the water on 4 November 1960 and on 9 October 1963.

The first event occurred at the Vajont reservoir while the artificial basin was filling up for the very first time. On 4 November 1960 a rock landslide, with a volume equal to $700000 \mathrm{~m}^{3}$, fell into the water causing an impulse water wave which was $2.0 \mathrm{~m}$ high and generated a $10 \mathrm{~m}$ wave runup on the dam (Semenza, 2002). Figure 7 reports a picture of the Vajont valley just after the 1960 landslide. At that moment, the reservoir surface was at $652 \mathrm{~m}$ over the m.s.l., the basin had a mean water depth equal to $160 \mathrm{~m}$, and contained $40000000 \mathrm{~m}^{3}$ of water. In the left panel of Fig. 8 it is possible to identify the section of the 1960 slide, along with its sliding surface, and it is possible to evaluate that the landslide front height was approximately equal to $10 \mathrm{~m}$. It is possible to assume that the slope inclination angle with the horizontal $\alpha$ was equal to $35^{\circ}$. Referring to the work of Semenza (2002), the analysis of the maps indicates a landslide width equal to $250 \mathrm{~m}$. As it was a very fast movement (Semenza, 2002), it is possible to assume an impact velocity of about $5-10 \mathrm{~m} / \mathrm{s}$, and a time of underwater landslide motion equal to $10-20 \mathrm{~s}$. The value of the observed maximum wave height, equal to $2.0 \mathrm{~m}$, is to be intended close to the dam: for this reason, an anomaly $\theta=90^{\circ}$ and a distance $r=480.0 \mathrm{~m}$ are considered. These values have been defined analyzing the map of the Vajont valley reported in Semenza (2002). About the 1960 event, no observations of wave runup are reported, and for this reason only the characterization of the maximum wave height generated by the landslide is here carried out. The values of the forecasted parameter $H_{\max }$ are plotted in 


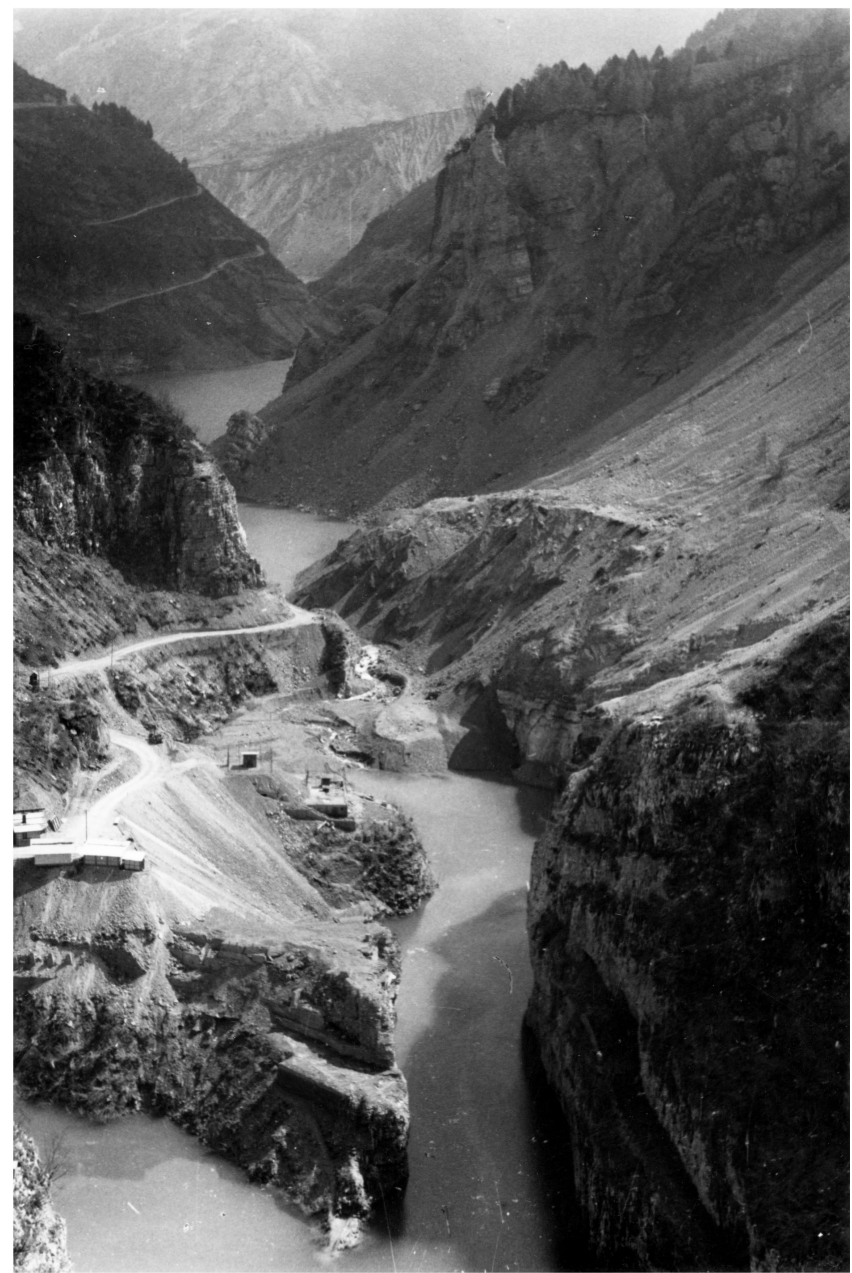

Fig. 7. Picture of the Vajont valley after the 1960 landslide event (picture taken from Semenza, 2002).

Fig. 9 considering a given uncertainty on the landslide time of underwater motion, assumed variable in the range (10.0; 20.0) $\mathrm{m} / \mathrm{s}$. It can be noticed that the maximum generated wave height is estimated to be satisfactorily close to the value of $2.0 \mathrm{~m}$ reported by Semenza (2002).

The event occurred on 9 October 1963 is one of the most catastrophic ever documented phenomenon of subaerial landslide generated waves. A 270 million $\mathrm{m}^{3}$ landslide detached from the Toc mountain and fell into the Vajont artificial reservoir, which had been filled up during the previous years. The presence of a very slow, ancient landslide movement in the Toc mountain was well known to everybody, and the word "Toc" means piece of rock in the local slang. The mountain was indeed affected by a paleo-slide (see Fig. 8). It is clear that the landslide movement was accelerated by the presence of water, which had been filled up in the artificial basin in a short amount of time (about 3 years) preceding the 1963 event. During those years, some geologists studied the landslide and realized that it was a giant Mshaped mechanism (Fig. 10). On 9 October 1963 the basin surface was at $700.42 \mathrm{~m}$ over the m.s.l., corresponding to a mean water depth equal to $200 \mathrm{~m}$, and contained about 120
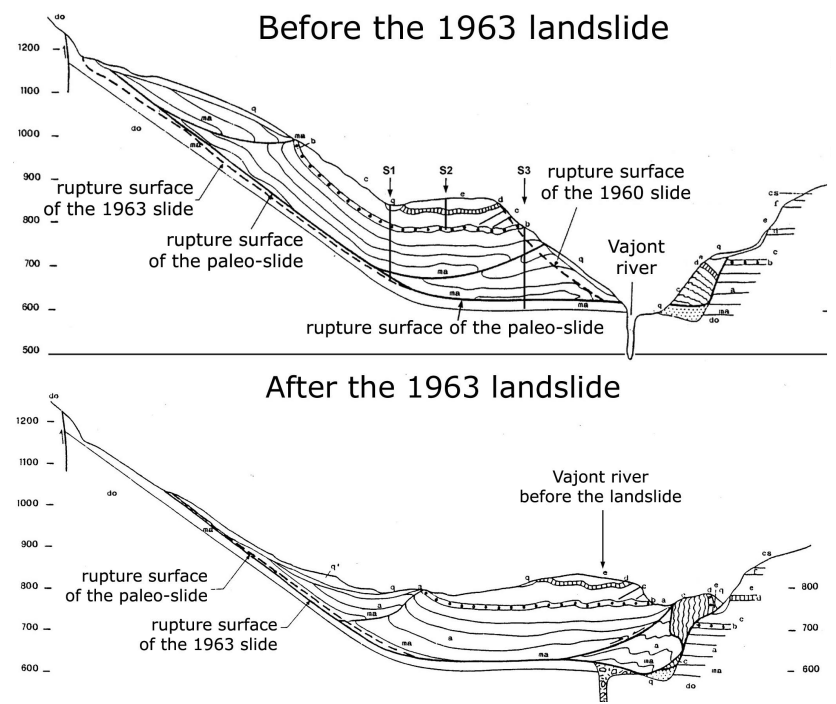

Fig. 8. Sections of the Vajont valley before and after 9 October 1963, landslide. The presence of paleo-slide at the Toc mountain is visible in both the panels, presenting a rupture surface very close to the rupture surface of the 1963 slide. A section of the landslide occurred in 1960 is also visible in the left panel (picture taken from Semenza, 2002).

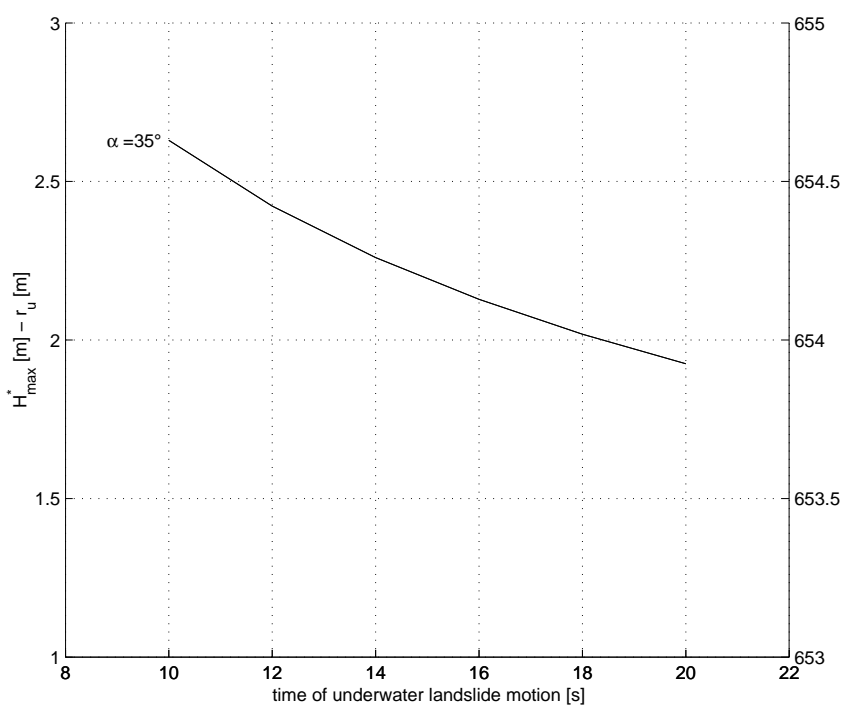

Fig. 9. Estimated maximum wave height $H_{\max }$ generated by the landslide event of 4 November 1960 occurred at the Vajont reservoir. The secondary y-axis refers to levels above the m.s.l.

millions $\mathrm{m}^{3}$ of water. The landslide generated a high impulse wave which flooded the opposite slope, reaching the height of $235 \mathrm{~m}$ above the basin water surface, right close to the city of Casso, propagated upstream the Vajont valley, and downstream, overtopping the dam and then destroying the city of Longarone. Figures 11 and 12 present two pictures of the Vajont valley just after 9 October 1963 landslide. Bearing in mind the aim of applying the experimental formulations to characterize the generated impulse waves, it is to be stressed that the considered event presented values 


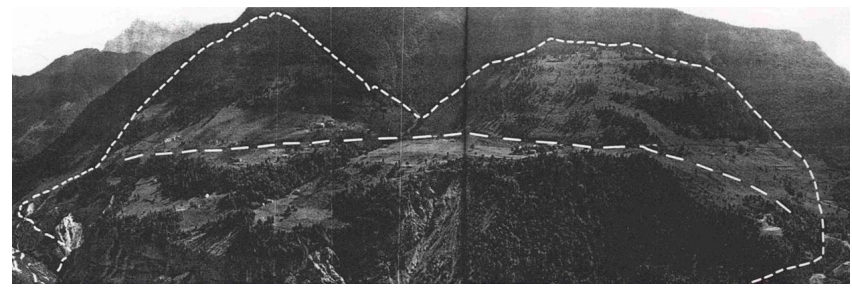

Fig. 10. Picture of the Toc mountain, taken by E. Semenza in 1959, reporting the first hypothesis about dimensions and shape of the landslide mechanism interesting the Vajont reservoir (picture taken from Semenza, 2002).

of physical parameters well outside the experimental ranges. However, we believe that the application of the forecasting formulation can still provide useful and reliable information about the generated impulse wave.

It is well known that the landslide mechanism was $2000 \mathrm{~m}$ wide: this value is also confirmed by the recent work of Datei (2003). As far as the landslide front height is concerned, a reasonable assumption is to consider a value of about $140 \mathrm{~m}$, as it can be deduced by the analysis of the geological sections presented by Semenza (2002), two of them being reported in Fig. 8. The seismic waves time series recorded at the Pieve di Cadore measuring station, which is reported in Fig. 13, demonstrates that the landslide mechanism took about 20.0$25.0 \mathrm{~s}$ to fall into the water. Assuming this hypothesis, the landslide impact velocity can be taken in the range (20.0; 25.0) $\mathrm{m} / \mathrm{s}$, as proposed also by Datei (2003). About the slope of the rupture surface of the landslide, Fig. 8 shows a low slope inclination angle close to the water, while it increases uphill. For this reason, the value of $\alpha$ is assumed variable in the range $\left(6.0^{\circ} ; 10.0^{\circ}\right)$. As far as the maximum generated wave is concerned, Semenza (2002) reports a runup value of $235.5 \mathrm{~m}$ in correspondence of the dam, which can be assumed to be at $\theta=0.0^{\circ}$ and $r=280.0 \mathrm{~m}$ from the landslide impact point. This assumption can be also testified by the damages on vegetation in the opposite slope, right close to the village of Casso, which is $964.0 \mathrm{~m}$ above the m.s.l., as it is visible in Fig. 11. About the inclination angle of this slope, a value of $\gamma=25^{\circ}$ was assumed.

With these hypotheses, the application of the forecasting formulations gives the estimates of $H_{\max }$ and $r_{u}$ reported in Fig. 14. It can be deduced that, even if the considered values are pretty outside the experimental ranges, reasonable assumptions give consistence to $H_{\max }$ and $r_{u}$ estimates, which are in a very satisfactorily agreement with the value of $210.0 \mathrm{~m}$ reported by Semenza (2002).

\section{Conclusions}

A research program on landslide generated water waves is currently being carried out at the Laboratory of Environmental and Maritime Hydraulic LIAM (Laboratorio di Idraulica Ambientale e Marittima) of L'Aquila University, funded by the Italian National Dam Office RID (Registro Italiano Dighe).
Table 4. Values of the non dimensional parameters calculated for the three considered real cases.

\begin{tabular}{lccc}
\hline & Pontesei 1959 & Vajont 1960 & Vajont 1963 \\
\hline$w h / d^{2}$ & $\mathbf{9 . 0 5}$ & 0.09 & $\mathbf{7 . 0}$ \\
$v / \sqrt{g d}$ & $\mathbf{0 . 0 2}$ & 0.19 & 0.50 \\
$\cos (\theta)$ & 1.0 & 0.0 & 1.0 \\
$\sin (\alpha)$ & 0.08 & 0.57 & 0.13 \\
$r / d$ & 4.04 & 3.0 & 1.4 \\
$t_{s}^{*}$ & $\mathbf{3 2 . 0}$ & 3.71 & 4.98 \\
$\gamma(\mathrm{rad})$ & 0.69 & & 0.43 \\
\hline
\end{tabular}

Part of the results obtained within the research program were used to define empirical formulation to forecast the principal features of the impulse generated waves as a function of the landslide mechanism. These formulations have been here applied in the study of three famous and tragic events of landslide generated waves occurred in two Italian artificial basins, which are the Pontesei and the Vajont reservoirs. In particular, the event occurred on 9 October 1963 at the Vajont reservoir is one of the most tragic every reported, due to the great loss of human lives.

It is clear that the study and the full understanding of a real case landslide generated waves event which presents complicated geometries and many physical parameters involved should be carried out using a dedicated experiment, as in the works of Davidson and McCartney (1975), Mader (1999) and Fritz et al. (2001), or a specifically implemented numerical model. The experimental study carried out within our research project aimed at the definition of empirical formulation which could be used to forecast the general features of the generated water waves in many real cases. Usually, when a landslide is expected to fall into a reservoir or in the open sea, there is no time to build physical models and perform experiment, or either to run numerical simulations, and is of the utmost importance having an order of magnitude of the expected phenomenon. The study presented in this paper showed that even though the selected real cases presented values of the involved parameters outside the experimented ranges, it is still possible to get useful information about the generated impulse waves by using the set of empirical formulations defined by the carried out experimental studies. Table 4 reports the values of the non dimensional parameters for the real cases considered in the present study. Values outside the ranges tested in the experimental study are reported in bold.

Introduced results showed that the considered empirical formulations well estimate the values of both the maximum generated wave height $H_{\max }$ and the wave runup $r_{u}$, in the considered three real cases occurred in the Pontesei and the Vajont artificial reservoirs. The comparison of results with the values deduced from the literature showed good satisfactorily agreement. 


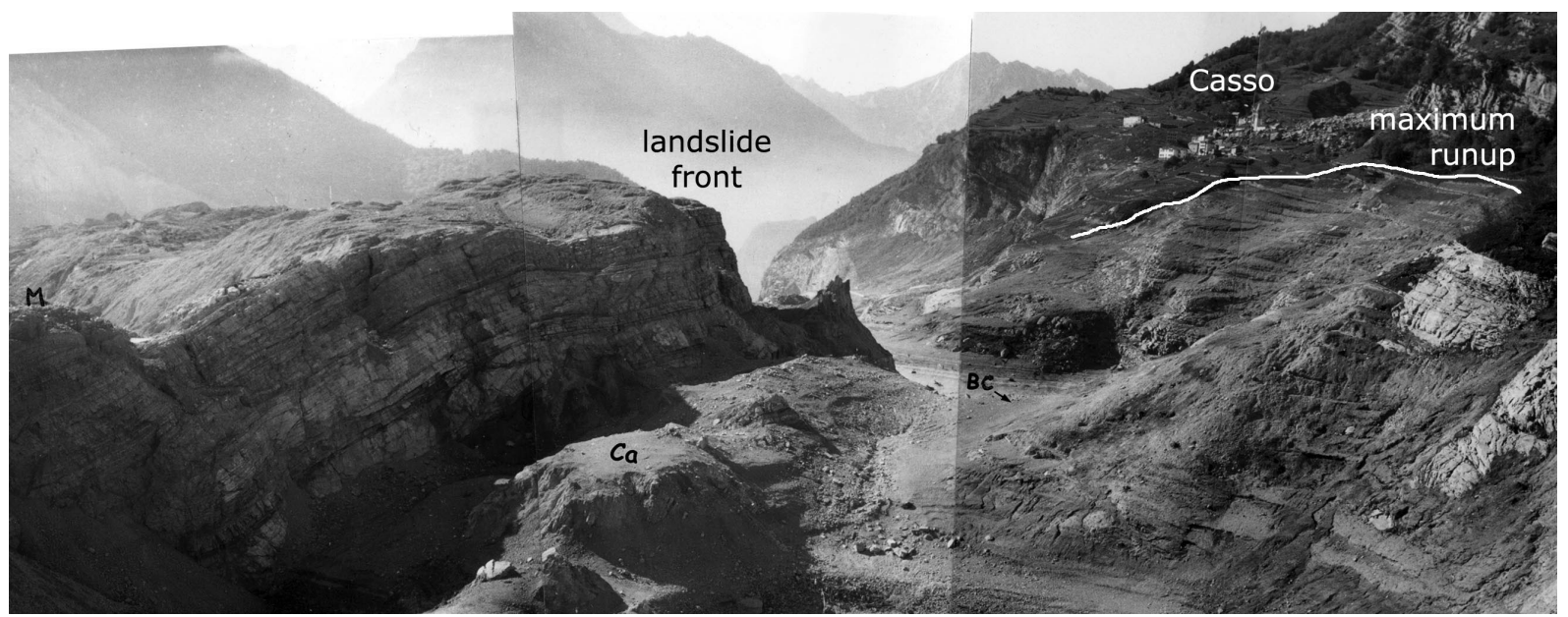

Fig. 11. Picture of the Vajont valley after 9 October 1963 landslide. On the right part of the picture the village of Casso is visible, while a white line reports the maximum runup level of the generated impulse wave.

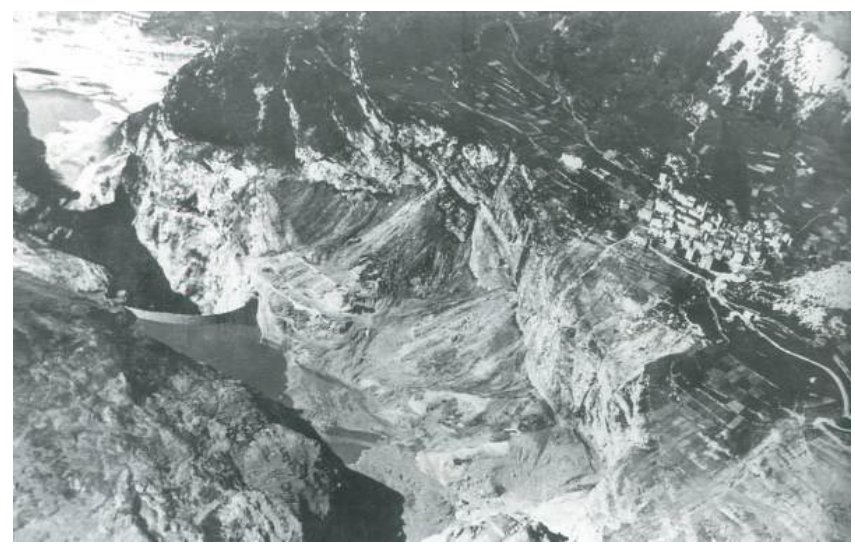

Fig. 12. The Vajont valley just after 9 October 1963, landslide event. In the left part of the picture it is possible to see the Vajont dam, as it is now, which was not damaged by the overtopping water.

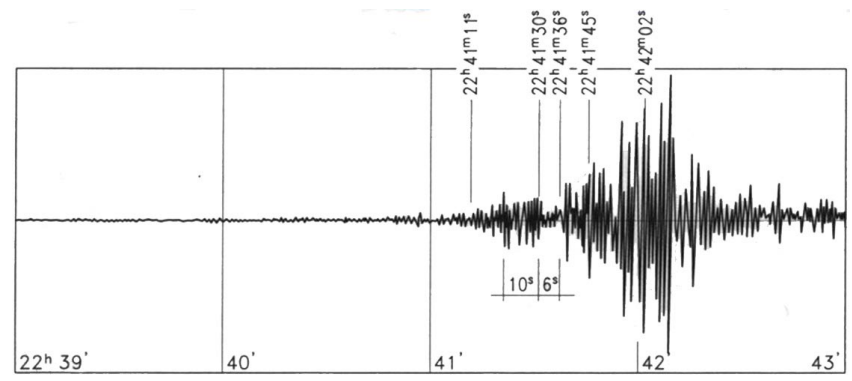

Fig. 13. Seismic wave record from the Pieve di Cadore measuring station showing the time the 1963 landslide mechanism took to fall into water, equal to $20.0-25.0 \mathrm{~s}$.

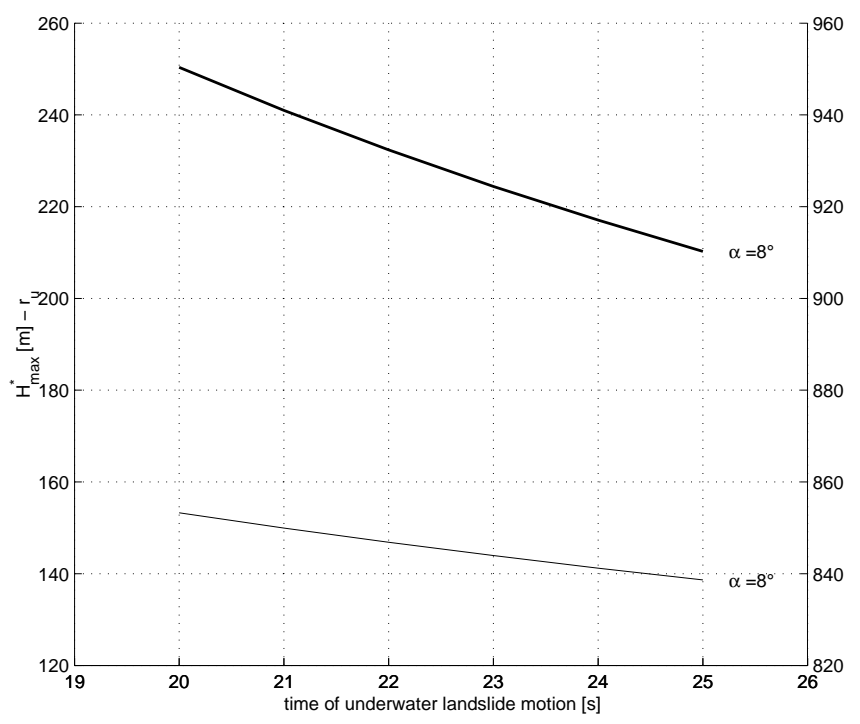

Fig. 14. Estimated maximum wave height $H_{\max }$ and $r_{u}$ generated by the 1963 event occurred at the Vajont reservoir. The secondary $y$-axis refers to levels above the m.s.l.

Acknowledgements. This work was funded by the Italian National Dam Office - RID (Registro Italiano Dighe), and by MIUR (COFIN 2004 "Onde di maremoto generate da frane in corpi idrici: meccanica della generazione e della propagazione, sviluppo di modelli previsionali e di sistemi di allerta in tempo reale basati su misure mareografiche"), whose scientific coordinator is P. De Girolamo. K-flash edition are gratefully acknowledged for the pictures taken from the work of Semenza (2002). The authors thank P. Semenza for the kind permission of the pictures, C. Datei for the many useful discussions, and the laboratory technicians M. Nardi and L. Matergia for the realization of the physical models.

Edited by: F. Guzzetti

Reviewed by: two referees 


\section{References}

Caratto, M., Semenza, E., and Turrini, M.: Study of bank instability of the Pontesei hydraulic reservoir (Belluno Province N.E. Italy.), in: Proceedings of the first European Conference on Landslides, Prague, 2002.

Datei, C.: Vajont, La storia idraulica, Cortina, Padova, 2003.

Davidson, D. D. and McCartney, B. L.: Water waves generated by landslides in reservoirs, ASCE Journal of the Hydraulics Division, 101 HY12, 1489-1501, 1975.

Di Risio, M.: Landslide generated impulsive waves: generation, propagation and interaction with plane slopes - An experimental and analytical study, Ph.D. thesis, Università degli studi di Roma Tre, Roma, 2005.

Di Risio, M. and De Girolamo, P.: Risalita di onde impulsive su piani inclinati, in Convegno di Idraulica e Costruzioni Idrauliche IDRA 2004, Trento, 2004.

Fritz, H. M., Hager, W. H., and Minor, H.-E.: Lituya Bay case: Rockslide impact and wave run-up., Sci. Tsunami Hazards, 19, 3-22, 2001.

Fritz, H. M., Hager, W. H., and Minor, H. E.: Near field characteristics of landslide generated impulse waves, ASCE J. Waterway, Port, Coastal and Ocean Eng., 130, 287-302, 2004.

Heinrich, P.: Nonlinear water waves generated by submarine and aerial landslides, ASCE J. of Waterways, Port, Coastal and Oc. Eng., 118, 249-266, 1992.

Huber, A. and Hager, W. K.: Forecasting impulse waves in reservoirs, in: Commission internationale des grands barrages, Dixneuvieme Congres des Grands Barrages, Florence, 993-1005, 1997.

Kamphuis, J. W. and Bowering, R. J.: Impulse waves generated by landslides, in: Proc. of 12th ICCE, ASCE, 575-588, 1972.

Kranzer, H. C. and Keller, J. B.: Water waves produced by explosions, J. Appl. Phys., 398-407, 1960.

Le Méhauté, B. and Wang, S.: Water waves generated by underwater explosion, World Scientific, 1996.

Mader, C. L.: Modeling the 1958 Lituya Bay mega-tsunami, Sci. Tsunami Hazards, 17, 57-67, 1999.

Monaghan, J. and Kos, A.: Scott Russell's wave generator, Physics of Fluids, 12, 622-630, 2000.
Muller, D. R.: Auflaufen und Überschwappen von Impulswellen an Talsperren - Runup and Overtopping of Impuse Waves at Dams, Ph.D. thesis, Eidg. Technische Hochschule ETH, Zurich, 1995.

Panizzo, A.: Physical and numerical modelling of subaerial landslide generated waves, Ph.D. thesis, Università degli studi di L'Aquila, L'Aquila, 2004.

Panizzo, A., De Girolamo, P., and Petaccia, A.: Forecasting subaerial landslide generated waves, J. Geophys. Res., accepted, 2005.

Prins, J. E.: Characteristics of waves generated by a local disturbance, Transactions, American Geophysical Union, 865-874, 1958.

Semenza, E.: La storia del Vajont, raccontata dal geologo che ha scoperto la frana., Tecomproject, Ferrara, 2002.

Stoker, J. J.: Water waves, Interscience: New York, 1957.

Synolakis, C. E.: The runup of solitary waves, J. Fluid Mech., 185, 523-545, 1987.

Tadepalli, S. and Synolakis, C. E.: The runup of N-waves on sloping beaches, Proc. R. Soc. Lond., 445, 99-112, 1994.

Walder, J. S., Watts, P., Sorensen, O. E., and Janssen, K.: Tsunamis generated by subaerial mass flows, J. Geophys. Res., 108, 22362255, 2003.

Watts, P.: Water waves generated by underwater landslides, Ph.D. thesis, California Inst. of Tech., Pasadena, CA, 1997.

Watts, P.: Wavemaker curves for tsunamis generated by underwater landslides, ASCE J. of Waterways, Port, Coastal and Oc. Eng., 124, 127-137, 1998.

Watts, P., Grilli, S. T., Kirby, J. T., Fryer, G. J., and Tappin, D. R.: Landslide tsunami case studies using a Boussinesq model and a fully nonlinear tsunami generation model, Nat. Hazards Earth Syst. Sci., 3, 391-402, 2005,

SRef-ID: 1684-9981/nhess/2003-3-391.

Wiegel, R. L.: Laboratory studies of gravity waves generated by the movement of a submarine body, Trans. Am. Geophys. Union, 36, 759-774, 1955.

Wiegel, R. L., Noda, E. K., Kuba, E. M., Gee, D. M., and Tornberg, G.: Water waves generated by landslides in reservoirs, ASCE J. of Waterways, Port, Coastal and Oc. Eng., ww2, 307-333, 1970. 